\title{
Enjoying Elephant Watching: A Study on Social Carrying Capacity of Kawdulla National Park in Sri Lanka
}

\author{
R. M. W. Rathnayake ${ }^{1}$ and U. A. D. P. Gunawardena ${ }^{2}$
}

1 Sabaragamuwa University of Sri Lanka, BelihulOya, Sri Lanka. warath1@gmail.com

2 University of Sri Jayewardenepura, Nugegoda, Sri Lanka. prasanthigunawardena@yahoo.com

\begin{abstract}
The goal of this study was to investigate the social carrying capacity (SCC) of Kawdulla National Park (KNP) in terms of vehicle crowding. Crowding was considered as the social norm to estimate the standards for SCC. The normative theory approach was applied in this study and a social norm curve was prepared. Based on the hypothesis visitor acceptability or tolerance influenced by vehicle crowding, images with different number of vehicles were generated. The crowding standard for SCC was estimated as 9 vehicles within $25 \mathrm{~m}$ radius by asking each respondent whether the presented scenarios were acceptable or not. Statistically, it was proven that socio economic status of visitors mainly affect on the acceptability of vehicle crowding. The average visitor acceptability for enjoying elephant watching has decreased with the increasing number of vehicles (crowding). Therefore the results of the present study could be applied in decision making to diversify the tourism activities in order to maintain the visitor satisfaction on enjoying elephant watching.
\end{abstract}

\section{Introduction}

In Sri Lanka, national parks are the only protected areas, which permit recreation. The national parks get more than half a million visitors a year, about $20 \%$ of who are foreigners. Presently, tourism is the fourth revenue earning industry in Sri Lanka (CBSL, 2010).

National parks have been charged with the dual mandate of providing for quality recreation opportunities and protecting park resources. Protected area managers in many parts of the world also share similar responsibilities. Tourism management in national parks and other protected areas is done for achieving the objectives of maximizing people's enjoyment of their stay, through education and recreation, minimizing impacts on habitat and wildlife and increasing the visitor's concern for conservation (Sale and Berkmueller, 1988). Therefore, the ultimate goal of tourism management, tourism planning 
and visitor services management is protecting natural resources and providing the high quality visitor experience.

In recreational planning, protected area managers are interested in recreational planning based on the results of conducted studies on visitor characteristics and perceptions, and rarely visitor carrying capacities (Sale and Berkmueller, 1988, Eagles et al., 2002). There are complaints found in the visitor complaints books in national parks in Sri Lanka mentioning less visitor satisfaction experience in the crowded national parks, but there have been no studies carried out in Sri Lanka on crowding and quality of visitor experience.

Visitor-induced impacts and resource degradation are highly considered in park and protected area management. Therefore, managing such issues requires information about social impacts and SCC in these protected areas (Burns et al., 2010). Although the issues and settings are often similar in scope, the study goals, methodological approaches, and variables often differ in specific countries because of different legal requirements, circumstances, and challenges.

All over the world, visitor management in nature-based recreational settings has been concerned with the natural resources conservation. For example, according to Arnberger (2006), Cessford and Muhar (2003), Kajala (2007), Sievänen et al., (2008) and Vuorio et al., (2003) the European countries have relied heavily upon visitor monitoring, and several countries have meanwhile established standardized visitor monitoring programs. This approach successfully provides indicators/and or norms to natural resource managers.

The carrying capacity concept was applied to parks and recreation management to address the relationship between visitor use, resource conservation and social conditions. The concept of carrying capacity was first introduced to the field of recreation management in the mid 1930s (Manning, 1999).

Kawdulla National Park (KNP) is a popular tourism destination for elephant watching, where hundreds of elephants could be seen. There are complaints on disturbance for enjoying the elephant watching due to vehicular traffic (crowding) in KNP, especially in weekends and public holidays. The national parks are managed by the Department of Wildlife Conservation (DWC) and so far DWC has not done any study on social carrying capacity to determine standards of vehicle crowding for maintaining the visitor satisfaction. The aim of present study is to determine social carrying capacity (SCC) in terms of vehicle crowding of KNP.

\section{Literature Review}

Further, Burns et al., (2010) mentioned that for developing SCC models variables like trip characteristics, socio-demographic variables, and recreation 
activities are highly considered. The variables reflecting the quality of the recreation experience, such as crowding perceptions, have rarely been asked (Arnberger and Mann, 2008). According to Arnberger and Mann (2008), Arnberger and Brandenburg (2007), Hennig (2006) and Kalisch and Klaphake (2008) during the past decade, interest in these variables has increased and recent efforts to provide valid and long-term data on overall visitation, visitor preferences and satisfaction, and even crowding perceptions are reported for several German, Swiss, and Austrian protected areas.

The concept of carrying capacity is often mentioned in the ecotourism literature. Carrying capacity is the maximum number of visitors who can visit an area without leading to severe environmental degradation or serious decline in the quality of the experience gained by visitors (Aylward et al., 1996, Mandziuk, 1995). Marin et al., (2011) also confirmed that the individual visitors are expected to be disturbed by different kinds of noise due to crowding through his studies, and showed that the human-caused noise detracts from the quality of the visitor experience in natural areas.

Carrying capacity can be measured in terms of the natural environment, the host community and the visitor. Factors measured are ecological (e.g., ecosystem health, ecosystem integrity), physical (trail areas, water quality and availability, lodging, sewer systems), social (e.g., over-crowding, traffic, pollution, waste disposal), and economic and managerial (e.g., locally owned enterprises, trained personnel) (Mandziuk, 1995).

SCC in relation to visitor satisfaction has been a long-standing issue in management of parks and protected areas. Contemporary carrying capacity frameworks rely on formulation of indicators and standards of quality to define and manage carrying capacity (Manning et al., 2005).

Visitor crowding and conflict are the two primary social or experiential impacts. Wagar (1964) first reported that crowding can decrease aesthetic enjoyment and diminish opportunities for solitude. Crowding was originally based on physical components measured in terms of visitor density, but later it has been conceptualized as psychological evaluations of visitor density (Gramann, 1982). Early research efforts reported that as user density increased, satisfaction decreased (Shelby, 1980), leading managers to focus on determining the permissible numbers of visitors that would prevent crowding. Visitor expectations, preferences and motives may be more important determinants of perceived crowding than actual visitor densities.

Moreover, natural and cultural resources can be degraded by excessive visitor use. In more formal terms, the use of some national parks, or 
portions thereof, have exceeded their carrying capacity (Mitchell, 1994, Wilkinson, 1995).

Contemporary carrying capacity frameworks, such as Limits of Acceptable Change (LAC) and Visitor Experience and Resource Protection (VERP), rely on formulation of standards of quality, which are defined as minimum acceptable resource and social conditions in parks and wilderness.

LAC approach concentrates on establishing measurable limits to human induced changes in the natural and social settings of parks and protected areas, and on identifying appropriate management strategies to maintain and / or restore desired conditions. That is knowledge of physical - biological environment is combined with knowledge of socio political context in order to define appropriate and acceptable future conditions. The LAC framework is thus based on resource management by objective.

Manning (2001) has recently referred to the evaluative component as the prescriptive component. The research process they propose (usually referred to as the normative approach) has been the dominant paradigm for empirically deriving evaluative standards (Manning et al., 1999, Vaske et al., 1993).

Visitor experience impacts can also have great recreational or social significance. Visitor crowding and conflicts reduce visitor satisfaction and may lead to the spatial or temporal displacement of visitors (visitors may go to other viewing points). This study explores the theory and application of carrying capacity to two national parks in Sri Lanka. Emphasis is placed on the development and application of LAC, a framework developed for managing carrying capacity in the U.S. national parks.

Within the past decade, however, critiques of this approach have emerged. Some critiques are of a technical nature. For example, empirical studies have shown that within-subject and within-population variability in norms (evaluative standards) can exceed between-area variability (Williams et al., 1992, Cole and Stewart, 2000). Others question whether normative research actually gets people's values (Roggenbuck et al., 1991). Questions have been raised about the population that is sampled, usually current on-site visitors. When subpopulations are mixed, management may inappropriately be directed at the needs and 
desires of an average visitor who does not exist (McCool and Cole, 2001). Equity issues are raised when studies only give voice to certain populations (Cole and Stewart, 2000).

In the application of the sustainable tourism indicators, the concept of carrying capacity is frequently used. This implies that the tourism destinations possess some limits in the volume and intensity that a specific geographic zone can bear without provoking any irreparable damage. Nevertheless, as Saveriades (2000) confirms, there is still neither a generally accepted definition nor a standard systematic procedure to assess this concept. One of the most renowned definitions was given by the World Tourism Organization (WTO, 1981), which signaled that carrying capacity represents the maximum number of visitors that a geographic or physical entity can receive without provoking an unacceptable alteration in the physical and social medium nor an unacceptable reduction in the quality of the visitors' experiences.

Recent experience with carrying capacity suggests that it can be applied most effectively through formulation of indicators and standards of quality for biophysical conditions (resource carrying capacity) and for the visitor experience (social carrying capacity) (Manning, 1999b, Manning, 2001, Graefe et al., 1990, Stankey et al., 1985, Stankey and Manning, 1986). Indicators of quality are measurable, manageable variables that define the quality of park and wilderness resources and the visitor experience. Standards of quality define the minimum acceptable condition of indicator variables.

'Normative theory' approach has been applied in some studies to identify the standards for crowding. Manning et al., (1997) applied the normative approach to estimate the crowding standards along the carriage road at Acadia National Park in the United States, where visitors were shown six digitally constructed scenarios (six range of visitor uses), and asked their acceptability on a scale -4 (very unacceptable) to +4 (very acceptable), but in the present study range of scale was from -1 (highly unacceptable) to +1 (highly acceptable).

Visual approaches to measure crowding and other outdoor recreation related norms have been developed. Computer software has been used to edit and provide photographs depicting a range of use levels and environmental impacts and visitor satisfaction at Arches National Park in (Manning et al., 1995, Hof et al., 1994).

In addition to normative theory approach, indifference curve analysis has been recently adapted to examine the Visitor Carrying Capacity (VCC) in Aches National Park ((Lawson and Manning, 2000, Lawson and Manning, 2002a, Lawson and Manning, 2002b). Stated choice analysis represents another research approach to quantify carrying capacity related values and trade off inherent in park and wilderness management. Recently, stated choice 
modeling has been adapted to carrying capacity analysis and applied at Denali National Park (Lawson and Manning, 2001a, Lawson and Manning, 2001b) and Yosemite National Park (Newman et al., 2001, Newman et al., 2002).

By formulating indicators and standards of quality, parks and wilderness can be managed within a defined carrying capacity. Indicator variables are monitored over time, and if standards of quality are violated (or are in danger of being violated), management action is required. This approach to carrying capacity is central to contemporary park and wilderness management frameworks including LAC (Stankey et al., 1985), and VERP (Manning, 2001). In Sri Lanka, VCC studies have not been done in protected areas, and as a result no proper visitor management plans have been prepared for national parks in Sri Lanka.

Burns et al., (2010) used 'logit model' to study how some socio-economic attributes and crowding affect the acceptance of crowding in three national parks i.e. Danube Floodplains National Park in Austria, the Harz National Park in Germany and the Hells Canyon National Recreation Area in the United States, where visitors are allowed walked along the nature trails. The results showed that the positive intercept indicates that the majority of the recreational scenarios were deemed as not contributing to displacement by the respondents. The utility curve for the number of people reflects an increasingly negative slope to twelve people per scene. The more people on the trail, the more participants were likely to displace from the trail. This attribute was the most important one, followed by the attribute placement.

\section{Methodology}

\section{Study site}

The KNP was declared as a national park on $1^{\text {st }}$ April 2002, and it is located approximately between the latitudes $6^{\circ} 47^{\prime} \mathrm{N}$ and the longitudes $80^{\circ} 46^{\prime \prime}$ and $80^{\circ} 50^{\prime} \mathrm{E}$ in the catchment of Kawdulla tank with an extent of 6690 ha. The KNP was established to protect the immediate catchment of the KNP reservoir and to provide a refuge or habitat for wild elephants, especially in the monsoon period.

The tank bed area is very attractive where hundreds of elephants could be seen in the dry season. In addition, waders within Kawdulla tank are an attractive scenery for visitors. The reservoir with perennial water supply and extensive grasslands provides an ideal habitat for elephants. Among these fauna, a considerable percentage of endemic and globally and nationally threatened vertebrate species are found in KNP. The park is accessible being $197 \mathrm{~km}$ away from Colombo. Hence, KNP is highly used for hundreds of elephant viewing. KNP is unique among the national parks of Sri Lanka as it enables 
to see elephants at any time of the day. In 2013 KNP received 20539 local visitors and 15775 foreign visitors for enjoying elephant watching. The total revenue from permit issuing was Rs. 21 million. It was found that annually there is $10 \%$ of visitor increment to the park.

\section{Theoretical aspects and estimation of SCC}

Within the context of carrying capacity, scientific approaches to park and wilderness related values have been applied primarily for the formulation of the standard of quality for indicators. The number of visitors in a given viewpoint is considered as an indicator, and the maximum acceptable number of visitors was estimated through the 'normative approach' which was widely used by Manning (2007).

A hypothetical social norm curve is shown in Figure 1 to illustrate normative theory and methods. The norm curve traces the average acceptability rating of the sample recreationists for encountering a range of groups of other visitors per day along a trail.

As research on normative standards has been started, several approaches to measure norms have evolved. In general, the outdoor recreation-related norms have been measured using a "numerical" or "narrative" approach. For example, respondents were asked to evaluate a range of encounters $(0$. $5,10,15$, etc.) with other groups per day along a nature trail. The normative data derived were aggregated and graphed to construct a "norm curve," from which social norms might be identified.

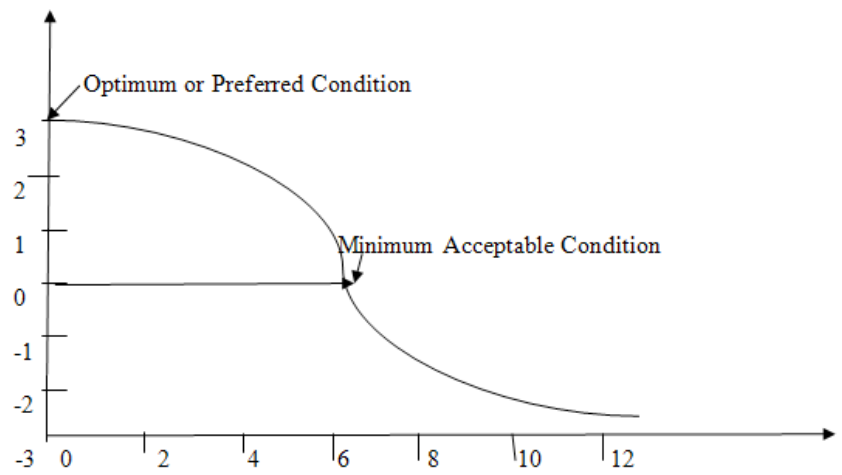

Figure 1: Hypothetical social norm curve (Source: Manning (2007))

An issue implicit in all of these measurement approaches concerns the evaluative dimension used in these questions. When respondents were asked to evaluate a range of use levels and related impacts, the response scale included terminology specifying a variety of evaluative dimensions including 
"acceptability", "preference", "pleasantness", "desirability", "satisfaction", and "tolerance". In this study, standards were established for crowding.

The relationship between crowding acceptance/satisfaction level and variables could be shown in a model:

\section{$C A=\int v$, age, educ, visitortype, surveyedday}

Where,

$\begin{array}{ll}\text { CA } & \text { : Crowding acceptance level } \\ \mathrm{V} & : \text { No. of visitors } / \text { vehicles } \\ \text { age } & : \text { Age in number of years } \\ \text { educ } & : \text { Education in number of years } \\ \text { visitortype } & : \text { Visitor type }(1=\text { foreign visitors, } 0=\text { local visitors }) \\ \text { surveyedda } & : \text { Surveyed day }(1=\text { weekends and public holidays, } 0=\text { week } \\ & \text { days, })\end{array}$

\section{Questionnaire and scenario development}

Saveriades (2000) defines the SCC as the maximum level of use that can be absorbed by an area without an unacceptable decline in the quality of experience of visitors and without an unacceptable adverse impact on the area's society. The two components of SCC are (1) the quality of experience that visitors will accept before seeking alternative destinations (that is to say, the tourists' psychological carrying capacity), and (2) the degree of tolerance of the host population to the presence of tourists (that is to say, the residents' psychological carrying capacity). Therefore, the satisfaction of the visitor could be found to decline when the levels of the tourist use a particular area are high. This concept is found in the normative approach, and scenarios were developed, increasing the number of visitors at a particular viewpoint, which is the tank bed area of KNP.

In the questionnaire, each scenario was numerically shown with photographs, and visitors were asked for their satisfaction on crowding at each viewpoint. For KNP, only one questionnaire was prepared (Appendix 1) because the scenic viewpoint in KNP is the tank bed area. There were 05 scenarios in the questionnaire. The number of vehicles within the $25 \mathrm{~m}$ radius while observing elephants is considered in developing the scenarios. The scenarios are as follows (Table 1):

Table 1: Number of vehicles for a particular scenario at KNP

\begin{tabular}{cc}
\hline Scenario & No. of vehicles within a 25 m radius \\
\hline 1 & $0-2$ \\
2 & $3-4$ \\
3 & $5-6$ \\
4 & $7-8$ \\
5 & $9-10$ \\
\hline
\end{tabular}


The above six acceptable levels of scenarios for HPNP and KNP were numerically numbered (Table 2).

Although different numerical values could be given for acceptable levels, in the present study the highly acceptable level is given +1.00 , and highly unacceptable level is given -1.00. Between these two values, the other numerical values are given proportionately for the acceptable levels. The results on acceptable levels against crowding were plotted to obtain the minimum level of acceptance, which will be the crowding standard.

Table 2: Numerical values for acceptable levels with vehicle crowding

\begin{tabular}{lc}
\hline \multicolumn{1}{c}{ Acceptable Level } & Numerical Value \\
\hline HA- Highly Acceptable & +1.00 \\
A - Acceptable & +0.50 \\
FA- Fairly Acceptable & +0.25 \\
FUA - Fairly Unacceptable & -0.25 \\
UA - Unacceptable & -0.50 \\
HUA- Highly Unacceptable & -1.00 \\
\hline
\end{tabular}

Data collection and data analysis

The sample size was 100 and the team leader or representative of every eighth visitor group to the park was interviewed at the tank bed area in the evening time. This study was conducted throughout the year and acceptable levels were recorded and social norm curve was drawn for KNP. The STATA 11 statistical package was used, and logit model was applied in data analysis. Visitor type and surveyed day were considered as dummy variables.

\section{Results and Discussion}

\section{Determination of SCC}

The greatest acceptability for visitor satisfaction is less than two vehicles at the viewpoint. After that the acceptability levels decreased dramatically with the increasing number of vehicles. The acceptability levels of the number of vehicles have decreased with the increasing number of vehicles within a $25 \mathrm{~m}$ radius at KNP tank bed area, and this is shown in Table 3. In addition, the number of vehicles against the sum of acceptability was plotted and social norm curve was drawn for KNP tank bed area (Figure 2). The minimum acceptability level was recorded between the vehicle numbers eight and ten. According to Figure 2 also, the social norm curve crosses the acceptability at nine vehicles at the viewpoint which indicates the vehicle carrying capacity standard for the KNP tank bed area. 
Table 3: Acceptability levels with a range of vehicles within $25 \mathrm{~m}$ radius at Kawdulla tank bed.

\begin{tabular}{|c|c|c|c|c|c|c|c|c|}
\hline \multirow{2}{*}{$\begin{array}{l}\text { No. of } \\
\text { Vehicles } \\
\text { within } \\
\text { a } 25 \mathrm{~m} \\
\text { radius }\end{array}$} & \multicolumn{6}{|c|}{ Acceptability } & \multirow{2}{*}{$\begin{array}{c}\text { Sum of } \\
\text { Acceptability }\end{array}$} & \multirow{2}{*}{$\begin{array}{c}\text { Acceptability } \\
\text { Level }\end{array}$} \\
\hline & 1 & 0.5 & 0.25 & -0.25 & -0.5 & -1 & & \\
\hline 2 & 100 & 0 & 0 & 0 & 0 & 0 & 100 & 1 \\
\hline 4 & 16 & 84 & 0 & 0 & 0 & 0 & 58 & 0.58 \\
\hline 6 & 8 & 47 & 43 & 2 & 0 & 0 & 41.75 & 0.42 \\
\hline 8 & 4 & 24 & 39 & 27 & 6 & 0 & 16 & 0.16 \\
\hline 10 & 0 & 13 & 21 & 22 & 21 & 23 & -27.25 & -0.27 \\
\hline 12 & 0 & 0 & 14 & 25 & 31 & 30 & -48.25 & -0.48 \\
\hline 14 & 0 & 0 & 0 & 5 & 51 & 44 & -70.75 & -0.71 \\
\hline 16 & 0 & 0 & 0 & 0 & 38 & 62 & -81 & -0.81 \\
\hline
\end{tabular}

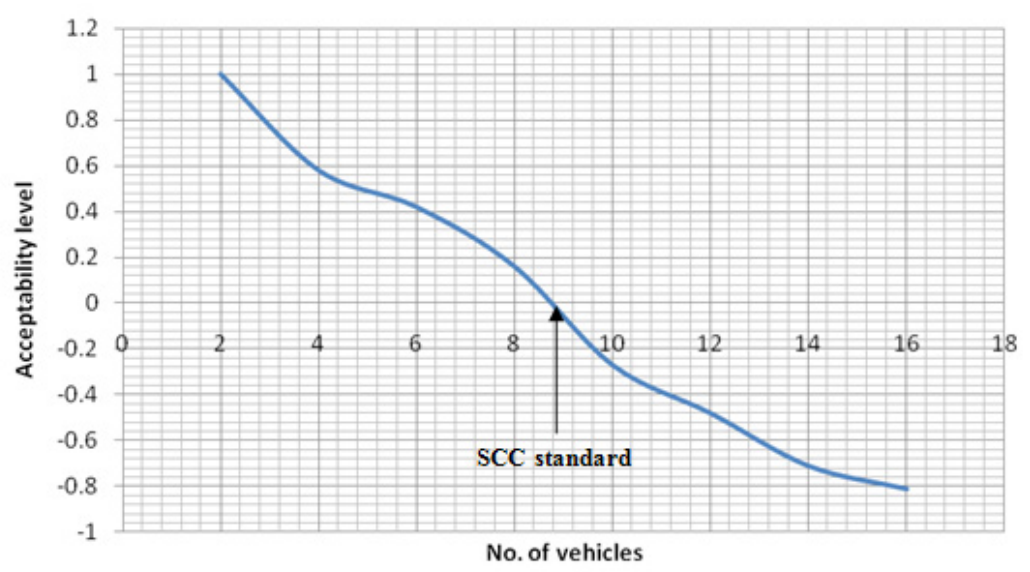

Figure 2: Social norm curve for the KNP tank bed

The social norm curve and regression equations clearly showed that the visitor acceptability levels reduce with increasing either the number of visitors at each viewpoint or the number of vehicles within a $25 \mathrm{~m}$ radius. Maintaining the number of visitors or vehicles at a particular viewpoint is important for visitor satisfaction and avoiding the displacement of visitors. In recreational planning, these standards should be maintained for enhancing the visitor satisfaction on less crowding.

\section{Relationship between crowding acceptance and socio-economic factors}

Table 4 shows the results of logit model which regressed, crowding acceptance levels versus respondents' socio-economic characteristics. Further, these tables present the logit model parameter coefficients, standard errors and $p$-values for 
each level of acceptance level. The acceptance levels are defined as (3- highly acceptable, 2- acceptable, 1-moderaly acceptable, '-1'-moderately acceptable, '-2' - unacceptable and '-3' - highly unacceptable). The most important attribute was the number of visitors depicted in the image. Overall, it is found that the number of vehicles is highly significant with the acceptance of crowding level. If the crowding is increased (the number of vehicles is high) the acceptance level will decrease gradually. Therefore, at highly acceptance, acceptance and moderately acceptance levels, the coefficients of variable 'number of vehicles' showed a negative value. Meanwhile, at highly unacceptable, unacceptable and moderately unacceptable levels the coefficient of the variable, 'number of vehicles' showed a positive relationship.

Except the variable 'visitors', other variables 'educ' (education) and 'age' are always positive with crowding acceptable levels. Generally, it is found that if the respondent is middle aged or senior citizen with a higher education level (in number of years), he or she does not accept the crowding. The coefficients 'age', and 'educ' are also significant with the increasing number of vehicles at a particular viewpoint. Visitor type and surveyed day whether week day or weekend or public holiday are not significant and do not affect on acceptability. Meanwhile the foreign visitor type is significant for highly acceptable levels. The low values of intercepts (constants) indicate that the majority of the depicted crowding scenarios were not tolerable for the respondents.

Table 4: Logistic function for vehicle crowding acceptability levels at KNP

\begin{tabular}{lrrrrrr}
\hline \multirow{2}{*}{ Variables } & \multicolumn{7}{c}{ Acceptability Level } \\
\cline { 2 - 7 } vehicles & \multicolumn{1}{c}{-3} & \multicolumn{1}{c}{-1} & \multicolumn{1}{c}{1} & \multicolumn{1}{c}{3} \\
& $1.806^{* * *}$ & $1.678^{* * *}$ & $1.086^{* * *}$ & $0.668^{* * *}$ & $-1.917^{* * *}$ & $-1.996^{* * *}$ \\
age & $(0.124)$ & $(0.121)$ & $(0.105)$ & $(0.0807)$ & $(0.225)$ & $(0.238)$ \\
& $0.0666^{* * *}$ & $0.0627^{* *}$ & $0.0459^{*}$ & $0.0620^{* * *}$ & $0.0614^{*}$ & $-0.0636^{*}$ \\
education & $(0.0294)$ & $(0.0288)$ & $(0.0261)$ & $(0.0207)$ & $(0.0321)$ & $(0.0334)$ \\
& 0.246 & 0.0839 & 0.00782 & -0.0994 & 0.193 & -0.183 \\
visitor type & $(0.180)$ & $(0.177)$ & $(0.159)$ & $(0.128)$ & $(0.205)$ & $(0.211)$ \\
& 0.100 & 0.0558 & 0.163 & 0.220 & 0.534 & $0.901^{* *}$ \\
surveyed day & $(0.418)$ & $(0.408)$ & $(0.374)$ & $(0.297)$ & $(0.325)$ & $(0.436)$ \\
& -0.194 & -0.280 & -0.166 & -0.114 & -0.146 & -0.225 \\
constant & $(0.410)$ & $(0.400)$ & $(0.362)$ & $(0.290)$ & $(0.378)$ & $(0.421)$ \\
& $-22.99^{* * * *}$ & $-18.90^{* * *}$ & $-11.04^{* * *}$ & $-5.835^{* * *}$ & $11.68^{* * *}$ & $12.55^{* * *}$ \\
& $(2.456)$ & $(2.356)$ & $(2.004)$ & $(1.513)$ & $(2.492)$ & $(2.626)$ \\
Observations & 800 & 800 & 800 & 800 & 800 & 800 \\
\hline
\end{tabular}

Standard errors in parentheses

$* * * \mathrm{p}<0.01, * * \mathrm{p}<0.05, * \mathrm{p}<0$

\section{SCC and infrastructure}

SCC determination is very important for visitor services and ecotourism planning process. Crowding may affect the goal of the visitor i.e. the visitor's 
recreational, educational enjoyment because crowding impacts may change the quality of recreational experience. Further, visitors may get attracted to another national park, wilderness areas or recreational areas or they may shift recreational product. The question is whether that change is accepted by the park managers and with existing legislation.

The social norm curve clearly showed that the visitor acceptability levels reduce with the increasing number of vehicles at each viewpoint. It is observed that the tank bed area of KNP is beyond the determined level of SCC, especially in weekends and public holidays because KNP get more visitors at weekends and public holidays. There is no limitation for the number of vehicles from the DWC. It was found that when KNP is crowded with more vehicles, visitors may be attracted by other alternative areas such as 'Hurulu Forest Park' at Gal Oya junction managed by the Forest Conservation Department - which is very close to KNP, where visitors are allowed to watch elephants at lower ticket prices. Therefore, it is important to manage the vehicle numbers to the park and diversify the visitor activities in KNP to manage visitors and to enhance their satisfaction.

It was revealed that the visitor infrastructure has not been improved based on a thematic systematic carrying capacity study. Consequently, park management can allow more visitors to the park in working days and limit the number of visitors to the park in weekends and public holidays. However, restricting visitor number and use is a poor method of managing resource impacts, because in most situations a little use causes considerable impact and further increases in use levels have less and less additional effect on the natural environment (Cole, 1987, Leung and Marion, 2000, Newsome et al., 2012). As such, this study has brought to represent a significant advancement to the field of SCC studies.

\section{Limitations and issues found in the study}

The task of drawing the social norm curves for visitors is an important aspect of this study. Vehicle numbers, proximity to others, unwanted visitor behaviour and complexity of the situation at high use situation due to the mix of users and movement directions could influence the respondents' decisions. Even at low numbers at the viewpoints, unwanted visitor behaviour influenced the tolerance of social conditions or acceptance remarkably.

Vehicle numbers, proximity to others and the mix of users influenced the respondents' decision to shift their use and acceptability levels at each viewpoint. In addition, unwanted visitor behaviour due to crowding may affect the visitor acceptability. These aspects should be considered in future studies. In the present study, only the crowding standards were studied to get information for recreational planning. The phenomenon of SCC is also highly 
relevant to the planning and implementation of recreational areas like national parks. Therefore, the calculated crowding standards for KNP could be applied for the visitor management.

All recreational activities cause some changes in the natural environment, and some of the changes could be considered as damages to the environment. Therefore, it is important that there should be some judgment about what conditions or standards ought to be in a particular area. This is a value judgment, and defined by various researchers (Wagar, 1974).

The main weakness of the normative approach is meaning evaluative dimensions used in the questionnaire i.e. a variety of dimensions ('acceptability', 'preference'. 'desirability' 'pleasantness', 'satisfaction' and 'tolerance'. These alternative evaluative dimensions have different meanings to respondents, and may result in significantly different personal and social norms (Manning, 2001). This was statistically proved by (Manning, 1999a 1999b, Manning, 2001).

\section{Conclusion and Recommendations}

The SCC for enjoying elephant watching in terms of vehicle carrying capacity of KNP was nine, and it was found that the standards of SCC or vehicle carrying capacity in KNP is met only at the weekends and on public holidays. Imposition of access restriction to the sites is a poor policy since it leads to the loss of visitors' welfare. Therefore, diversification of recreational activities in addition to the elephant watching will be the most possible solution. If the recreational activities are diversified, visitors will be dispersed in the study areas. Congestion will be minimized and satisfaction levels on elephant watching can be enhanced. Further, it is important to review the existing legislation for accommodating recreational activities and ecotourism concessions in the diversification of recreational activities. In addition, it is proposed to prepare visitor impact monitoring plans for each national park to mitigate the impact on natural resources due to increased visitation under the proposed scenarios. Further, so far there have not been any SCC studies for national parks in Sri Lanka, and therefore the present study is important in determining the SCC at other national parks in Sri Lanka.

\section{References}

Arnberger, A. (2006). Recreation use of urban forests: An inter-area comparison. Urban forestry and urban greening, 4, 135-144.

Arnberger, A. and Brandenburg, C. (2007). Past on-site experience, crowding perceptions, and use displacement of visitor groups to a peri-urban national park. Environmental Management, 40, 34-45. 
Arnberger, A. and Mann, C. (2008). Crowding in European forests: a review of recent research and implications for forest management and policy. Forestry, 81, 559-571.

Aylward, B., Allen, K., Echeverría, J. and Tosi, J. (1996). Sustainable ecotourism in Costa Rica: the Monteverde cloud forest preserve. Biodiversity and Conservation, 5, 315-343.

Burns, R. C., Arnberger, A. and Von Ruschkowski, E. 2010. Social Carrying Capacity Challenges in Parks, Forests, and Protected Areas. International Journal of Sociology, 40, 30-50.

CBSL 2010. Annual Report,. CBSL, Colombo, Sri Lanka.

Cessford, G. and Muhar, A. (2003). Monitoring options for visitor numbers in national parks and natural areas. Journal for Nature Conservation, 11, 240-250.

Cole, D. N. (1987) Research on soil and vegetation in wilderness: A stateof-knowledge review. Lucas, RC (compiler) Proceedings: National Wilderness Research Conference-Issues, State-of-Knowledge, Future Directions, General Technica Report INT-220. Ogden, UT, USDA Forest Service, Intermountain Research Station, 135-177.

Cole, D. N. and Stewart, W. P. (2000). Variability of user-based evaluative standards for backcountry encounters Leisure Sciences, 24, 313-324.

Eagles, P. F., Mccool, S. F. and Haynes, C. D. (2002). Sustainable tourism in protected area: guidelines for planning and management, World Conservation Union.

Graefe, A., Kuss, F. R. and Vaske, J. J. (1990). Visitor Impact Management: A Review of Research, Washington, DC, National Parks and Conservation Association.

Gramann, J. H. (1982). Toward a behavioral theory of crowding in outdoor recreation: An evaluation and synthesis of research. Leisure Sciences, 5, 109-126.

Hennig, S. (2006). Going Ahead: From Visitor Monitoring to Recreational Use Monitoring-The Example of the EU Regional Recreation Area Berchtesgaden National Park/Salzburger Kalkhochalpen. Exploring the Nature of Management, 322.

Hof, M., Hammett, J., Rees, M., Belnap, J., Poe, N., Lime, D. and Manning, R. (1994). Getting a handle on visitor carrying capacity: A pilot project at Arches National Park. Park Science, 14, 11-13. 
Kajala, L. (2007). Visitor monitoring in nature areas: A manual based on experiences from the Nordic and Baltic countries, Nordic Council of Ministers.

Kalisch, D. and Klaphake, A. (2008) The dilemma of recreational use versus nature protection-Responses from National Park authorities in Austria, Germany and Switzerland. Management for Protection and Sustainable Development. The Fourth International Conference on Monitoring and Management of Visitor Flows in Recreational and Protected Areas, 404408.

Lawson, S. and Manning, H. (2000). Crowding versus access at Delicate Arch, Arches National Park: an indifference curve analysis. Third Symposium on Social Aspects and Recreation Research. Arizona State University.

Lawson, S. and Manning, H. (2001a). Crossing experiential boundaries: visitor preferences regarding tradeoffs among social, resource, and managerial attributes of the Denali wilderness experience. The George Wright Forum.

Lawson, S. and Manning, H. (2001b). Evaluating multiple dimensions of visitors' tradeoffs between access and crowding at Arches National Park using indifference curve analysis. 2000 Northrastern Recreation Research Symposium,. U.S. Department of Agriculture Forest Service, Northeastern Research Station.

Lawson, S. and Manning, H. (2002a). Solitude versus access: a study of tradeoffs in outdoor recreation using indifference curve analysis. Leisure Sciences 23, 179-191.

Lawson, S. R. and Manning, R. E. (2002b). Tradeoffs among social, resource, and management attributes of the Denali wilderness experience: A contextual approach to normative research. Leisure Sciences, 24, 297312.

Leung, Y.-F. and Marion, J. L. (2000). Recreation impacts and management in wilderness: A state-of-knowledge review. Cole, DN, McCool, SF, Borrie, WT, O'Loughlin, J.,(comps), Proceedings: Wilderness Science in a Time of Change, 5.

Mandziuk, G. (1995). Ecotourism: A marriage of conservation and capitalism. Plan Canada, 35, 29-33.

Manning, R. E., Mccool, S. F. and Graefe, A. R. (1995) Trends in carrying capacity. Fourth International Outdoor Recreation and Tourism Trends Symposium and the 1995 National Recreation Resource Planning Conference. 
Manning, R., Ballinger, N., Valliere, W., Wang, B. and Jacobi, C. (1997). Acadia National Park Carriage Road Study: Phase III Research. U. S. National Park Service. Technical Report NPS/NESORNR/NRTR/98-1. Boston: National Park Service.

Manning, R. E., Valliere, W. A. and Wang, B. (1999). Crowding norms: Alternative measurement approaches. Leisure Sciences, 21, 97-115.

Manning, R. (1999a). Crowding and carrying capacity in outdoor recreation: from normative standards to standards of quality. Leisure Studies: Prospects for the Twenty-First Century. State College, PA: Venture Publishing, 323-34.

Manning, R., E. (1999b). Studies in Outdoor Recreation: Search and Research for Satisfaction (2nd ed.), Canada, Oregon State University Press.

Manning, R., Leung, Y.-F. and Budruk, M. (2005). Research to support management of visitor carrying capacity of Boston Harbor Islands. Northeastern Naturalist, 12, 201-220.

Manning, R. E. (2001). Carrying capacity as "informed judgement": The values of science and the science of values. USDA Forest Service Proceedings

Manning, R. E. 2007. Parks and carrying capacity: Commons without tragedy, Island Press.

Marin, L. D., Newman, P., Manning, R., Vaske, J. J. and Stack, D. (2011). Motivation and acceptability norms of human-caused sound in Muir Woods National Monument. Leisure Sciences, 33, 147-161.

Mccool, S. F. and Cole, D. N. (2001) Thinking and acting regionally: toward better decisions about appropriate conditions, standards, and restrictions on recreation use. The George Wright Forum. 85-98.

Mitchell, J. (1994). Our National parks. National Geographic, 186(4), 1-55.

Newman, P., Manning, R. and Valliere, W. (2002) Integrating resource, social and managerial indicators of quality into carrying capacity decisionmaking Integrating resource, social and managerial indicators of quality into carrying capacity decision-making. 2001 Northeastern Recreation Research Symposium. U.S. Department of Agriculture Forest Service, Northeastern Research Station, 233-238.

Newman, P., Marion, J. and Cahill, K. (2001) Integrating resource, social, and managerial indicators of quality into carrying capacity decision-making. The George Wright Forum. 28-40.

Newsome, D., Moore, S. A. and Dowling, R. K. (2012). Natural area tourism: Ecology, impacts and management, Channel View Books. 
Roggenbuck, J. W., Williams, D. R., Bange, S. P. and Dean, D. J. (1991). River float trip encounter norms: Questioning the use of the social norms concept. Journal of Leisure Research, 23, 133-153.

Sale, J. B. and Berkmueller, K. (1988). Manual of wildlife techniques for India.

Saveriades, A. (2000). Establishing the social tourism carrying capacity for the tourist resorts of the east coast of the Republic of Cyprus. Tourism management, 21, 147-156.

Shelby, B. (1980). Crowding models for backcountry recreation. Land Economics, 56, 43-55.

Sievänen, T., Arnberger, A., Dehez, J., Grant, N., Jensen, F. S. and SkovPetersen, H. (2008). Forest recreation monitoring: a European perspective.

Stankey, G. H., Cole, D. N., Lucas, R. C., Petersen, M. E. and Frissell, S. S. (1985). The limits of acceptable change (LAC) system for wilderness planning, USDA.

Stankey, G. H. and Manning, R. (1986). Carrying capacity of recreation settings. A Literature Review. The President's Commission on Americans Outdoors, 47-58.

Vaske, J. J., Donnelly, M. P. and Shelby, B. (1993). Establishing management standards: Selected examples of the normative approach. Environmental Management, 17, 629-643.

Vuorio, T., Emmelin, L. and Sandell, K. (2003). Methods for monitoring outdoor recreation and tourism in large nature areas.

Wagar, J. A. (1964). The carrying capacity of wild lands for recreation. Forest Science, 10.

Wagar, J. A. (1974). Recreational carrying capacity reconsidered. Journal of forestry, 72, 274-278.

Wilkinson, T. (1995). Crowd Control. National Parks, 69 (7-8), 36-41.

Williams, D. R., Roggenbuck, J. W., Patterson, M. E. and Watson, A. E. (1992). The variability of user-based social impact standards for wilderness management. Forest Science, 38, 738-756.

WTO (1981). Saturation of Tourist Destinations: Report of the Secretary General. Madrid, WTO. 